\title{
CORRECTION
}

View Article Online

View Journal I View Issue

Cite this: RSC Adv., 2020, 10, 27531

DOI: $10.1039 / d 0 r a 90080 j$

rsc.li/rsc-advances
Check for updates

\section{Correction: Development and characterization of a babassu nut oil-based moisturizing cosmetic emulsion with a high sun protection factor}

\author{
Michael Jackson Ferreira da Silva, ${ }^{a}$ Alisson Mendes Rodrigues, ${ }^{\mathrm{b}}$ Italo Rennan Sousa \\ Vieira, ${ }^{c}$ Gelmires de Araújo Neves, ${ }^{b}$ Romualdo Rodrigues Menezes, ${ }^{b}$ Eloisa da Graça \\ do Rosário Gonçalves ${ }^{d}$ and Maria Célia Pires Costa*e \\ Correction for 'Development and characterization of a babassu nut oil-based moisturizing cosmetic \\ emulsion with a high sun protection factor' by Michael Jackson Ferreira da Silva et al., RSC Adv., 2020, \\ 10, 26268-26276, DOI: 10.1039/DORA00647E.
}

The authors regret that the name of one of the authors (Maria Célia Pires Costa) was shown incorrectly in the original article. The corrected author list is as shown above.

The Royal Society of Chemistry apologises for these errors and any consequent inconvenience to authors and readers. 